Article

\title{
Method for Aluminum Oxide Thin Films Prepared through Low Temperature Atomic Layer Deposition for Encapsulating Organic Electroluminescent Devices
}

\author{
Hui-Ying Li *, Yun-Fei Liu, Yu Duan, Yong-Qiang Yang and Yi-Nan Lu * \\ Computer Science and Technology Department, Jilin University, Changchun 130012, Jilin, China; \\ E-Mails: liyray@gmail.com (Y.-F.L.); duanyu@jlu.edu.cn (Y.D.); yangyq12@mails.jlu.edu.cn (Y.-Q.Y.) \\ * Authors to whom correspondence should be addressed; \\ E-Mails: lihuiying@jlu.edu.cn (H.-Y.L.); luyn@jlu.edu.cn (Y.-N.L.).
}

Academic Editor: Erik Reimhult

Received: 5 November 2014 / Accepted: 27 January 2015 / Published: 10 February 2015

\begin{abstract}
Preparation of dense alumina $\left(\mathrm{Al}_{2} \mathrm{O}_{3}\right)$ thin film through atomic layer deposition (ALD) provides a pathway to achieve the encapsulation of organic light emitting devices (OLED). Unlike traditional ALD which is usually executed at higher reaction $\mathrm{n}$ temperatures that may affect the performance of OLED, this application discusses the development on preparation of ALD thin film at a low temperature. One concern of ALD is the suppressing effect of ambient temperature on uniformity of thin film. To mitigate this issue, the pumping time in each reaction cycle was increased during the preparation process, which removed reaction byproducts and inhibited the formation of vacancies. As a result, the obtained thin film had both high uniformity and density properties, which provided an excellent encapsulation performance. The results from microstructure morphology analysis, water vapor transmission rate, and lifetime test showed that the difference in uniformity between thin films prepared at low temperatures, with increased pumping time, and high temperatures was small and there was no obvious influence of increased pumping time on light emitting performance. Meanwhile, the permeability for water vapor of the thin film prepared at a low temperature was found to reach as low as $1.5 \times 10^{-4} \mathrm{~g} /\left(\mathrm{m}^{2} \cdot\right.$ day $)$ under ambient conditions of $25^{\circ} \mathrm{C}$ and $60 \%$ relative humidity, indicating a potential extension in the lifetime for the OLED.
\end{abstract}

Keywords: atomic layer deposition; lower temperature; uniform thin film 


\section{Introduction}

In recent years, research areas and novel applications focusing on organic light emitting devices (OLEDs) have developed rapidly [1-4]. However, there are still many problems that are inhibiting large scale industrialization of OLEDs. One of the critical bottlenecks is the lifetime of these devices, because of the deleterious impact of water vapor and oxygen on these devices, as first noted by Adachi et al. [5]. In the air, the light emitting intensity of OLEDs was found to decrease by $99 \%$ within $150 \mathrm{~min}$. When OLEDs worked, it was essential to inject electrons into the cathode, requiring cathode metals with lower work functions such as aluminum, magnesium, calcium. However, these metals readily react with any water vapor which is introduced into the devices, causing the notable decline in OLEDs lifetime. In addition, the water vapor could react with the hole transport layer and electron transport layer, and provide another potential mechanism for device failure [6]. Therefore, effective encapsulation of OLEDs is required to isolate each functional layer from water vapor and oxygen in air, thus prolonging the lifetime of the devices. In recent years, flexible OLEDs have become an area of major research. One of the major issues with flexible OLEDs is that a traditional glass cover plate encapsulation cannot satisfy the flexibility requirement. In lieu of this, thin film encapsulation (TFE) has been introduced to replace traditional glass cover plate encapsulation because dense thin films can be created with sufficient isolation from water and oxygen in the air. TFE can also effectively improve the mechanical properties of the device $[7,8]$.

A number of thin film encapsulation methods have been developed by scholars from different countries. Yamashita et al. [9] encapsulated OLEDs via formation of thermal chemical vapor deposition polymer films, which quadrupled the lifetime of the device. Kyokyun [10] took advantage of electron beam physical vapor deposition to prepare magnesium oxide thin films with a thickness of $2100 \mathrm{~nm}$. They also reported an obtained water vapor transmission rate (WVTR) decline to $0.2 \mathrm{~g} /\left(\mathrm{m}^{2} \cdot\right.$ day), which prolonged the lifetime of prepared OLED device by five times. Huang et al. [11] reported that the lifetime of encapsulated OLEDs containing a single-layer of PECVD SiNx was $600 \mathrm{~h}$ as compared to $6 \mathrm{~h}$ for a bare device. Heeger et al. [12] encapsulated devices by spin-coating Cytop ${ }^{\mathrm{TM}}$ (a type of perchloro polymer, obtained from Bellex International, Wilmington, DE, USA) as the water vapor barrier, and found that the half-life of the device increased more than five times. Meyer et al. [13] prepared a water vapor and oxygen barrier with $\mathrm{Al}_{2} \mathrm{O}_{3} / \mathrm{ZrO}_{2}$ nano laminates prepared through Atomic Layer Deposition (ALD) method. The technique was found to eliminate pinholes and surface defects significantly in the encapsulated thin film, thus reducing the corrosion of $\mathrm{Al}_{2} \mathrm{O}_{3}$. The thin film deposited via the ALD method was dense and smooth. With a thickness of only $130 \mathrm{~nm}$, they were able to obtain a WVTR of $4.7 \times 10^{-5} \mathrm{~g} /\left(\mathrm{m}^{2}\right.$. day $)$ at $70 \%$ relative humidity at $70{ }^{\circ} \mathrm{C}[13,14]$. Vitex Systems in the United States developed the Barix ${ }^{\mathrm{TM}}$ encapsulation technique that alternatively deposited acrylic resin monomer and inorganic thin film to form a flexible OLED which could block permeability of water vapor and oxygen. The performance of Barix ${ }^{\mathrm{TM}}$ barrier could be controlled by changing the number of layers and chemical composition of acrylic resin and inorganic material layer. The thin film produced by Barix ${ }^{\mathrm{TM}}$ had visible light transmittance higher than $80 \%$, and a roughness average $(\mathrm{Ra})$ of less than $10 \mathrm{~nm}$, with a water vapor transmissivity of $10^{-4}-10^{-6} \mathrm{~g} /\left(\mathrm{m}^{2} \cdot\right.$ day $)$, making Barix ${ }^{\mathrm{TM}}$ one of the most recognized encapsulation methods [15]. The reviews on research progress of encapsulation techniques for OLED thin films in recent years show electron beam evaporation, thermal evaporation and sputtering can deposit 
materials with high melting points, like oxide materials. However, the quality of thin film prepared by these methods is relatively low, and small cracks may occur as the deposited thin film becomes thicker, which can decline gas barrier properties during long-term storage of OLEDs. Compared to these methods, ALD method injects precursors, in the form of pulses, alternately into the reaction chamber. The precursors are uniformly adsorbed on substrate's surface, and simultaneously form bonds. In one cycle, only one atom layer is formed so that the uniformity of thin film prepared is better and a more dense structure is obtained [16]. The ALD method can accurately control the thickness of the inorganic passivation layer at the nanometer size range, and allows for preparation of a dense and non-porous thin film which isolates the permeability of water vapor and oxygen effectively. Ghosh et al. [17] used a single $\mathrm{ALD}-\mathrm{Al}_{2} \mathrm{O}_{3}$ layer encapsulation to extend OLED's lifetime, prepared in over $100{ }^{\circ} \mathrm{C}$. Report from Park et al. [18] showed that even with $\mathrm{AlO}$ x film of $30 \mathrm{~nm}$ would decreased WVTR to $0.0615 \mathrm{~g} /\left(\mathrm{m}^{2} \cdot\right.$ day $)$. However, the deposition rate of ALD is relatively low, and the sample has to be heated continually for more than $10 \mathrm{~h}$ to obtain encapsulation layer with thickness of $100 \mathrm{~nm}$ [6]. This raises concerns with OLEDs since organic materials have lower thermal stability than inorganic materials, the long-term heating at the temperature higher than the glass transition temperature of organic material may also cause degradation of devices. Because of this, only the preparation of encapsulation thin film at low temperatures (below the glass transition temperature of organic material) is valuable to the practical application and industrialization of ALD. More reports of ALD thin films are summarized in Table 1, including $\mathrm{ALD}-\mathrm{Al}_{2} \mathrm{O}_{3}$ at low temperature. Excellent barrier properties have been report during ALD processes at relatively high temperature. Plasma-enhanced atomic layer deposition, known as PEALD, enable deposition at low temperature, due to its high energetic radicals. However, reports showed that thin films deposited by PEALD exhibit poor WVTR, which was over $10^{-2} \mathrm{~g} /\left(\mathrm{m}^{2} \cdot \mathrm{day}\right)$. Therefore, improved barrier properties are required with ALD process at low temperature.

Table 1. Summary of the barrier properties of thin films including material, deposition condition and barrier performance.

\begin{tabular}{ccccccc}
\hline Process & Materials & Deposition condition & $\begin{array}{c}\text { Barrier layer } \\
\text { structure }\end{array}$ & $\begin{array}{c}\text { WVTR } \\
\left(\mathbf{g} / \mathbf{m}^{2} / \mathbf{d a y}\right)\end{array}$ & $\begin{array}{c}\text { OLED } \\
\text { lifetime }\end{array}$ & Ref. \\
\hline PEALD & $\mathrm{Al}_{2} \mathrm{O}_{3}: \mathrm{N}$ & $\mathrm{TMA}, \mathrm{O}_{2}, \mathrm{~N}_{2}$ temp $: 80^{\circ} \mathrm{C}$ & $300 \mathrm{~nm}$ thick & $\mathrm{N} / \mathrm{D}$ & $650 \mathrm{~h} 80{ }^{\circ} \mathrm{C}$, & {$[19]$} \\
& & & $50 \%$ & \\
$\mathrm{ALD}$ & $\mathrm{Al}_{2} \mathrm{O}_{3}$ & $\mathrm{TMA}, \mathrm{H}_{2} \mathrm{O}$ temp $: 120^{\circ} \mathrm{C}$ & $25 \mathrm{~nm}$ thick & $1.7 \times 10^{-5}\left(38{ }^{\circ} \mathrm{C}\right)$ & $\mathrm{N} / \mathrm{D}$ & {$[6]$} \\
$\mathrm{ALD}$ & $\mathrm{Al}_{2} \mathrm{O}_{3}$ & $\mathrm{TMA}, \mathrm{H}_{2} \mathrm{O}$ temp $: 80^{\circ} \mathrm{C}$ & $30 \mathrm{~nm}$ thick & $0.0615\left(90{ }^{\circ} \mathrm{C}\right)$ & $193 \mathrm{~h}$ & {$[18]$} \\
PEALD & $\mathrm{Al}_{2} \mathrm{O}_{3}$ & $\mathrm{TMA}, \mathrm{O}_{2}$ temp: $100^{\circ} \mathrm{C}$ & $10-40 \mathrm{~nm}$ thick & $5 \times 10^{-3}(\mathrm{RT})$ & $\mathrm{N} / \mathrm{D}$ & {$[20]$} \\
PEALD & $\mathrm{TiO}_{2}$ & TDMAT, $\mathrm{O}_{2}$ temp: $90{ }^{\circ} \mathrm{C}$ & $80 \mathrm{~nm}$ thick & $0.024(\mathrm{RT})$ & $90 \mathrm{~h}$ & {$[21]$} \\
\hline
\end{tabular}

In this article, the thin film that is used as a barrier to water vapor and oxygen was prepared using the ALD method, at low temperatures $80^{\circ} \mathrm{C}$, the surface roughness measured by atomic force microscopy (AFM) deposited at a low temperature were identical to the corresponding values of films deposited by the conventional process at higher temperatures. The ultrathin films showed perfect encapsulation properties, and a low WVTR of $1.5 \times 10^{-4} \mathrm{~g} /\left(\mathrm{m}^{2}\right.$. day) tested at ambient conditions of $25{ }^{\circ} \mathrm{C}$ and $60 \%$ relative humidity $(\mathrm{RH})$, could be achieved with thickness of $80 \mathrm{~nm}$, which is truly attractive compared with Barix ${ }^{\mathrm{TM}}$ of $5 \mu \mathrm{m}$ thickness, constructed during complex CVD-UV curing cycles. Compared with Ghosh et al. and Park et al. [8,17], the film showed relatively better WVTR within process of low 
temperature conditions. Furthermore, the compatibility of the low temperature $\mathrm{Al}_{2} \mathrm{O}_{3}$ for organic electronics was studied by measuring I-V-L and lifetime of OLEDs. The results demonstrate ALD process at $80{ }^{\circ} \mathrm{C}$, did not cause damage to the organic functional layers, providing a favorable barrier properties for OLEDs.

\section{Experimental Section}

Growth of $\mathrm{Al}_{2} \mathrm{O}_{3}$ thin films was completed on silicon wafer using the ALD method. The silicon wafer was scrubbed and washed with acetone, ethanol, and deionized water, and then cleaned for 10 min by these solvents under ultrasonication. The silicon wafer was then dried under nitrogen, baked $10 \mathrm{~min}$, and placed into a glove box. The vacuum level in ALD reaction chamber was at the range of $1 \times 10^{-2}$ to $3 \times 10^{-2} \mathrm{~Pa}$, and the temperature of the ventilation pipe for ALD equipment was set at $120{ }^{\circ} \mathrm{C}$. The internal temperature of reaction chamber and pumping gas time (PGT) were adjusted during the experiment as needed. Before thin film growth occurs, the substrate, in this instance a silicon wafer, must first been covered with a layer of hydroxyl groups. The precursor, trimethylaluminium (TMA) is injected into the reaction chamber first in the form of pulses, in order to react with hydroxyl groups on surface of silicon wafer. The reaction product $(-\mathrm{O}-) \mathrm{Al}\left(\mathrm{CH}_{3}\right)_{2}$ is adsorbed on the substrates surface, while gaseous reaction by-products, like $\mathrm{CH}_{4}$ and excess TMA precursor, are removed from reaction chamber under the help of inert gas. After the first reaction sequence is completed, water vapor as oxidant, is injected into reaction chamber to react with the adsorbed reaction product in the first reaction sequence. When the reaction reaches saturation, the products and excess moisture are removed from the reaction chamber by inert gas. This allows the monolayer of $\mathrm{Al}_{2} \mathrm{O}_{3}$ with hydroxyl-covered surface to be obtained. The reactions just discussed are shown in the following Formulae (1):

$$
\begin{gathered}
-\mathrm{OH}(\mathrm{ad})+\mathrm{Al}\left(\mathrm{CH}_{3}\right)_{3}(\mathrm{~g}) \rightarrow-\mathrm{O}-\mathrm{Al}\left(\mathrm{CH}_{3}\right)_{2}(\mathrm{ad})+\mathrm{CH}_{4}(\mathrm{~g}) \\
(-\mathrm{O}-) \mathrm{Al}\left(\mathrm{CH}_{3}\right)_{2}(\mathrm{ad})+\mathrm{H}_{2} \mathrm{O}(\mathrm{g}) \rightarrow(-\mathrm{O}-) \mathrm{Al}(\mathrm{OH})_{2}(\mathrm{ad})+2 \mathrm{CH}_{4}(\mathrm{~g})
\end{gathered}
$$

In the above formulas, $(\mathrm{ad})$ denotes surface-adsorbed state, and $(\mathrm{g})$ denotes a gaseous state. By repeating above steps, certain thicknesses can be obtained. Since the growth thickness is constant in every cycle, the grown thickness of thin film can be manipulated by controlling the number of cycles completed. In this study, the $\mathrm{Al}_{2} \mathrm{O}_{3}$ thin film was deposited with 2500 cycles at $80{ }^{\circ} \mathrm{C}$, and the multi-point thin film thickness was determined, by ellipsometry, as $223.76 \mathrm{~nm}$ (using data fitting, the mean square error (MSE) was 1.501), which was consistent with the prediction by ALD reaction cycles (the predicted thickness of the $\mathrm{Al}_{2} \mathrm{O}_{3}$ thin film after 2500 cycles was $225 \mathrm{~nm}$ ).

To determine the ALD reaction window temperature, the measure of decreasing the temperature was adopted together with regulation of PGT to a suitable value. It was found that continual uniform deposition through low temperature ALD could be achieved by extending input time of inert gas and increasing PGT at the low temperature to prevent the pollution between two gas precursors and inhibit any CVD reactions which may occur. For exploring the differences of $\mathrm{Al}_{2} \mathrm{O}_{3}$ thin film performance brought by high and low temperature ALD deposition, $\mathrm{Al}_{2} \mathrm{O}_{3}$ thin films of $50 \mathrm{~nm}$ were prepared respectively at $200{ }^{\circ} \mathrm{C}$, PGT $=10 \mathrm{~s}$ and $80{ }^{\circ} \mathrm{C}$, PGT $=30 \mathrm{~s}$. The contact angle measurement, SEM observations as well as AFM analysis were carried out to evaluate these differences. The thickness of the deposited $\mathrm{Al}_{2} \mathrm{O}_{3}$ was determined by Woollam variable-angle spectroscopic ellipsometer. Scanning 
electron microscopy (SEM) was conducted with a field-emission SEM (JSM-6700F, JEOL, Tokyo, Japan) operated at an accelerating voltage of $10 \mathrm{kV}$, and the samples were coated with a thin layer of gold $(5 \mathrm{~nm})$ before analysis. The root-mean-square (RMS) roughness and other surface features of the films were measured with a Veeco AFM (Plainview, NY, USA). Water contact angles were measured using a Kruss contact angle goniometer (Model DSA30), where the sessile drop of 2-3 $\mu \mathrm{L}$ in volume was dispensed with a microsyringe.

The WVTR was measured via electrical analysis on corrosion calcium (Ca) thin film [22]. Through measuring the I-V curves of calcium thin film with different exposure durations in air after encapsulation, the electric resistance can be obtained using equation (2):

$$
\operatorname{WVTR}\left[\mathrm{g} / \mathrm{m}^{2} \cdot \mathrm{day}\right]=-n \times \delta_{\mathrm{Ca}} \times \rho_{\mathrm{Ca}} \times \frac{d}{d t}\left(\frac{1}{R}\right) \times \frac{\mathrm{M}\left(\mathrm{H}_{2} \mathrm{O}\right)}{\mathrm{M}(\mathrm{Ca})} \times \frac{\text { Ca_Area }}{\text { Window_Area }}
$$

where $\mathrm{n}$ is the molar ratio ( $n=2$ for this system); $\delta_{\mathrm{Ca}}$ is the electrical resistivity $\left(3.91 \times 10^{-8} \Omega \mathrm{m}\right)$; $\rho_{\mathrm{Ca}}$ is the density of calcium $\left(1.55 \mathrm{~g} / \mathrm{cm}^{3}\right) ; 1 / \mathrm{R}$ is the measured electrical conductance; $\mathrm{M}\left(\mathrm{H}_{2} \mathrm{O}\right)$ and $\mathrm{M}(\mathrm{Ca})$ are the molecular weights of water and calcium respectively ( $18 \mathrm{~g} / \mathrm{mol}$ and $40 \mathrm{~g} / \mathrm{mol})$.

The Ca electrical measuring system was composed of the stable electricity cell controlled by a computer and the probe. The structure of device for calcium test was shown in Figure 1. The $200 \mathrm{~nm}$ Ca thin film and $100 \mathrm{~nm}$ aluminum electrode were coated onto the glass substrate. The imaged electrode and $\mathrm{Ca}$ thin film in this experiment were obtained via addition of a shield template before evaporation. The area of $\mathrm{Ca}$ thin film $(10 \mathrm{~mm} \times 10 \mathrm{~mm})$ was encapsulated and $\mathrm{Al}$ was exposed to act as electrode.

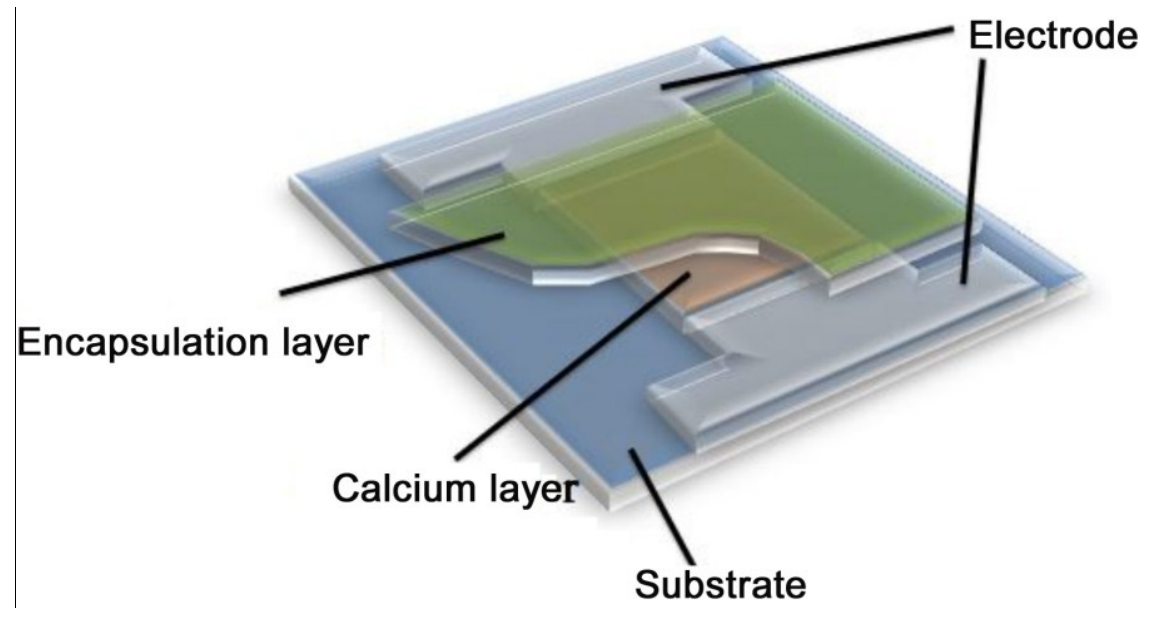

Figure 1. The structure of the device used for the calcium test.

\section{Results and Discussion}

Using the ALD method, $80 \mathrm{~nm} \mathrm{Al}_{2} \mathrm{O}_{3}$ thin films were formed on $\mathrm{Si}$ substrate at both $80{ }^{\circ} \mathrm{C}$ and $200{ }^{\circ} \mathrm{C}$. The water contact angles of both samples were measured and the corresponding surface energies were calculated from results, as shown in Table 2. 
Table 2. The water contact angles and surface energies of thin films deposited through Atomic Layer Deposition (ALD) under different conditions.

\begin{tabular}{ccc}
\hline Conditions & Water contact angles & Surface energy $(\mathbf{m N} / \mathbf{m})$ \\
\hline $\mathrm{Si}\left(80^{\circ} \mathrm{C}, \mathrm{PGT}=30 \mathrm{~s}\right)$ & $73.4^{\circ}$ & $39.6 \pm 0.2$ \\
$\mathrm{Si}\left(200^{\circ} \mathrm{C}, \mathrm{PGT}=10 \mathrm{~s}\right)$ & $68.9^{\circ}$ & $39.8 \pm 0.2$ \\
\hline
\end{tabular}

The contact angle corresponds, quantitatively, to surface wettability, and the surface energy can be calculated from contact angle using the Owens' equations [23]. The measurement of the contact angle can indicate the effect of different growth conditions on the formation of thin films since the surface energy is related to surface atom arrangement and internal structures. The data in Table 1 shows that both contact angles of ALD thin film at two temperatures were less than $90^{\circ}$, and that the difference in surface energy were $39.6 \pm 0.2 \mathrm{mN} / \mathrm{m}\left(80{ }^{\circ} \mathrm{C}, \mathrm{PGT}=30 \mathrm{~s}\right)$ and $39.8 \pm 0.2 \mathrm{mN} / \mathrm{m}\left(200{ }^{\circ} \mathrm{C}, \mathrm{PGT}=10 \mathrm{~s}\right)$, respectively, which verifies that the surface atom arrangement of $\mathrm{Al}_{2} \mathrm{O}_{3}$ thin film deposited via ALD at $80{ }^{\circ} \mathrm{C}$ is nearly identical to that of the $\mathrm{Al}_{2} \mathrm{O}_{3}$ thin film deposited via ALD at $200{ }^{\circ} \mathrm{C}$.

Figure 2a,b showed the SEM images of cross area of $\mathrm{Al}_{2} \mathrm{O}_{3}$ thin film deposited via low temperature $\operatorname{ALD}\left(80{ }^{\circ} \mathrm{C}\right.$, PGT $\left.=30 \mathrm{~s}\right)$ and high temperature ALD $\left(200{ }^{\circ} \mathrm{C}\right.$, PGT $\left.=10 \mathrm{~s}\right)$ respectively, with magnification of $20,000 \times$. Both surfaces of the two thin films were smooth, and the quality of the formed thin films was high. It was also found that the uniformity of the films were close to one another, and neither appeared "S" warped, creased, or cracked. Figure 3a,b shows the AFM morphology of the $\mathrm{Al}_{2} \mathrm{O}_{3}$ thin films deposited via low temperature $\operatorname{ALD}\left(80^{\circ} \mathrm{C}, \mathrm{PGT}=30 \mathrm{~s}\right)$ and high temperature $\operatorname{ALD}\left(200^{\circ} \mathrm{C}\right.$, PGT $=10 \mathrm{~s}$ ), respectively. The results show the roughness of the thin film formed at $80{ }^{\circ} \mathrm{C}$ and $200{ }^{\circ} \mathrm{C}$ are $0.304 \pm 0.030$ and $0.278 \pm 0.028 \mathrm{~nm}$, respectively. Both of them were found to have similar surface uniformity. This fact implied atomically smooth surface possessed by a stick 2D layer-by-layer growth mode at both higher and lower deposition temperature cases, since the extend PGT at the low temperature to prevent the reaction between two gas precursors and inhibit any CVD reactions which may lead to rough surface [23].

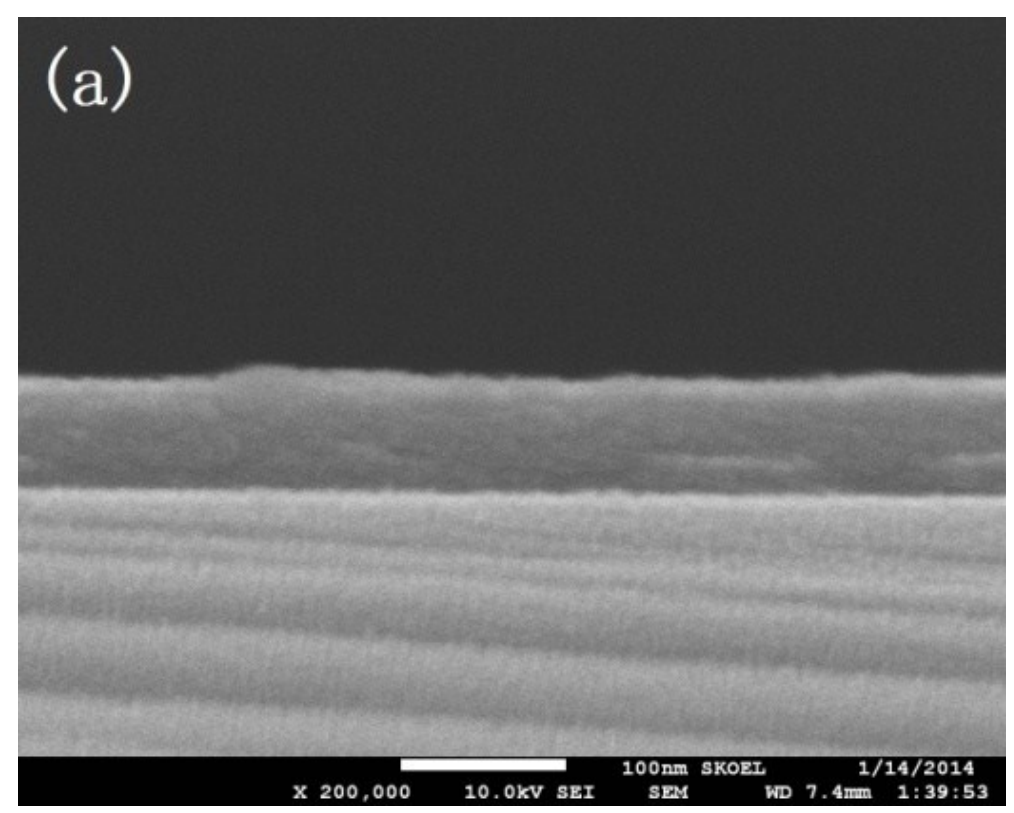

Figure 2. Cont. 


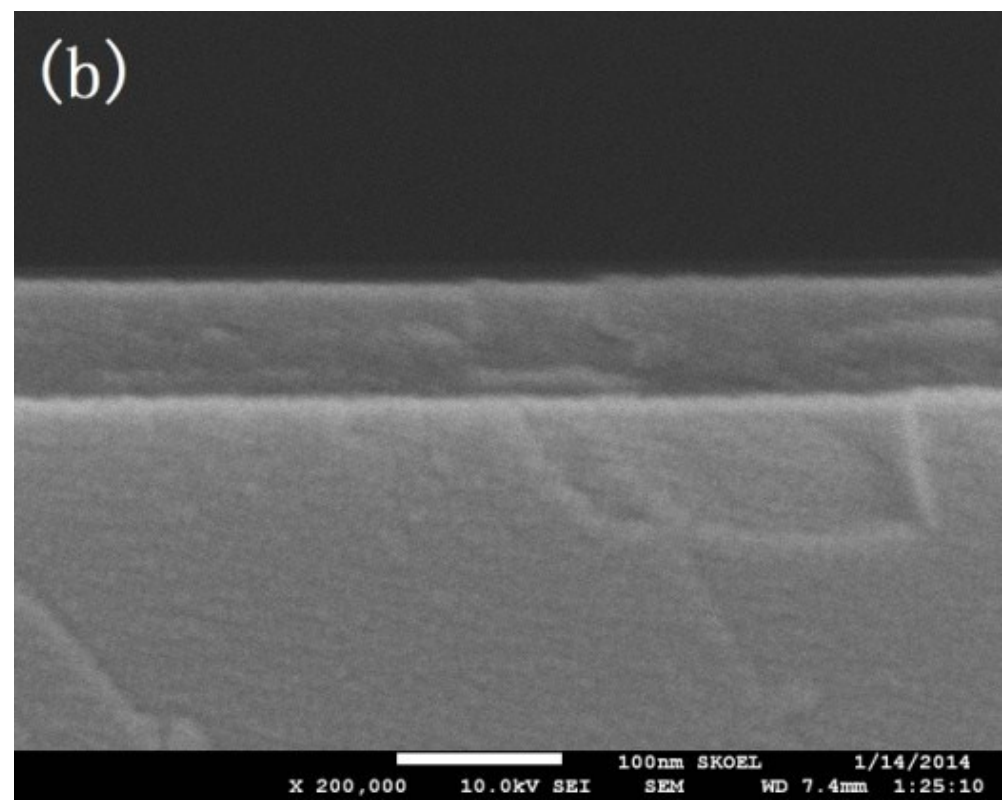

Figure 2. Cross-section SEM images of $\mathrm{Al}_{2} \mathrm{O}_{3}$ : (a) $80{ }^{\circ} \mathrm{C}$-based $\mathrm{Al}_{2} \mathrm{O}_{3}$; (b) $200{ }^{\circ} \mathrm{C}$-based $\mathrm{Al}_{2} \mathrm{O}_{3}$.

(a)

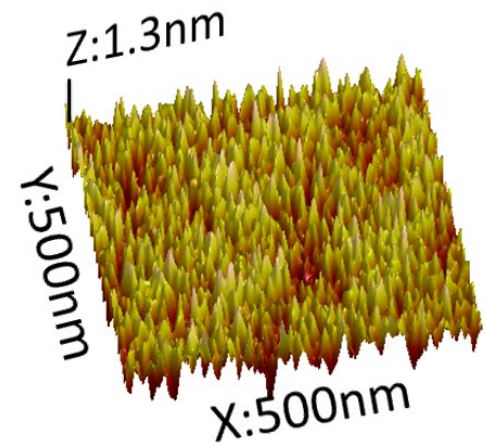

(b)

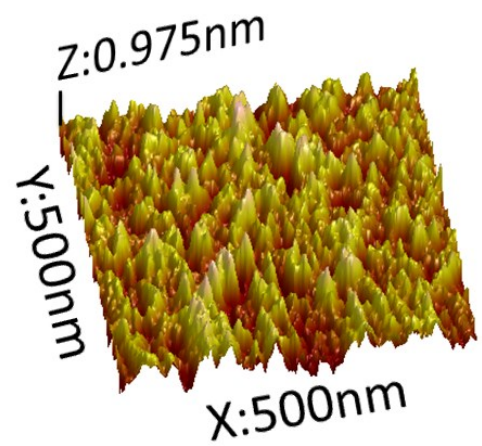

Figure 3. 3D Atomic Force Microscopy (AFM) images of $\mathrm{Al}_{2} \mathrm{O}_{3}$ film at deposition conditions: (a) $80{ }^{\circ} \mathrm{C}$, PGT $=30 \mathrm{~s}$; and (b) $200{ }^{\circ} \mathrm{C}$, PGT $=10 \mathrm{~s}$. The scan area in AFM experiment was $1.0 \mu \mathrm{m} \times 1.0 \mu \mathrm{m}$.

The water vapor permeability of $\mathrm{Al}_{2} \mathrm{O}_{3}$ thin films deposited via low temperature $\mathrm{ALD}\left(80{ }^{\circ} \mathrm{C}\right.$, $\mathrm{PGT}=30 \mathrm{~s})$ and high temperature $\operatorname{ALD}\left(200^{\circ} \mathrm{C}, \mathrm{PGT}=10 \mathrm{~s}\right)$ were measured by the Ca electrical method discussed earlier, and summarized in Figure 4 which depicts the $1 / \mathrm{R}$ curve with respect to time in the $\mathrm{Ca}$ test, with the black and red lines highlighting the normalized $\mathrm{Ca}$ test curves of $80 \mathrm{~nm} \mathrm{Al}_{2} \mathrm{O}_{3}$ encapsulation prepared at $80{ }^{\circ} \mathrm{C}$ and $80 \mathrm{~nm} \mathrm{Al}_{2} \mathrm{O}_{3}$ encapsulation prepared at $200{ }^{\circ} \mathrm{C}$, respectively. The water permeability of the thin films was obtained by calculating the slope of the curve at each time point. Based on the principle of the Ca test, after reaction with water and oxygen, the reacted portion of the $\mathrm{Ca}$ electrode has a lower electrical conductance, which will increase the electrical resistance of thin film, as represented by the decrease of conductance in the curve. The calculated WVTRs of single-layered $80 \mathrm{~nm}$-thickness $\mathrm{Al}_{2} \mathrm{O}_{3}$ thin films were $8.6 \times 10^{-4} \mathrm{~g} /\left(\mathrm{m}^{2} \cdot\right.$ day $)\left(200{ }^{\circ} \mathrm{C}, \mathrm{PGT}=10 \mathrm{~s}\right)$ and $1.5 \times 10^{-4} \mathrm{~g} /\left(\mathrm{m}^{2} \cdot\right.$ day $)\left(80{ }^{\circ} \mathrm{C}, \mathrm{PGT}=30 \mathrm{~s}\right)$, respectively. The inset of Figure 4 shows WVTRs of both $\mathrm{Al}_{2} \mathrm{O}_{3}$ thin films prepared at $80{ }^{\circ} \mathrm{C}$ and $200{ }^{\circ} \mathrm{C}$ with different thickness. The comparison between water permeability of encapsulation thin film at low and high temperatures indicated that the thin films 
prepared at low temperature have higher barrier performance. This result implies that $80 \mathrm{~nm}$-thick $80{ }^{\circ} \mathrm{C}$-PGT 30 s-based $\mathrm{Al}_{2} \mathrm{O}_{3}$ films may have excellent protection properties when integrated on OLEDs.

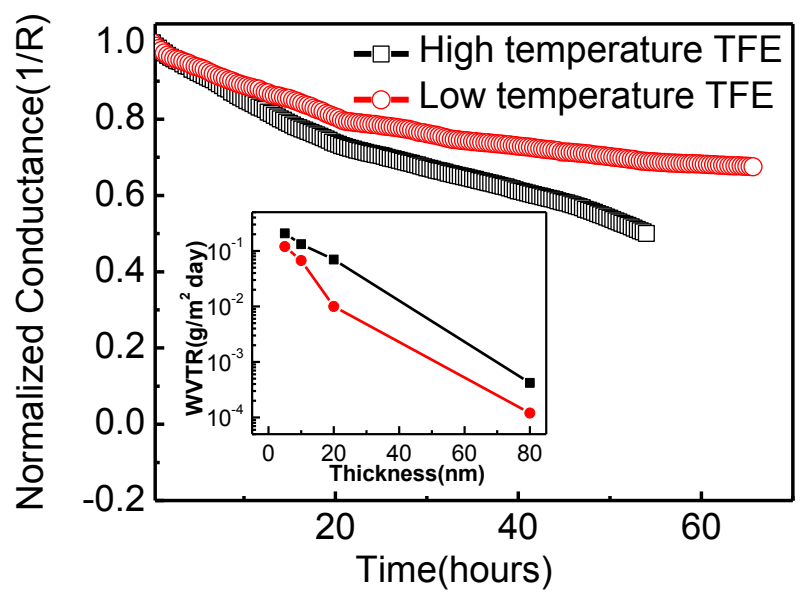

Figure 4. Normalized change in electrical conductance of Ca corrosion tests with $\left(80{ }^{\circ} \mathrm{C}\right.$, PGT $=30 \mathrm{~s}) \mathrm{Al}_{2} \mathrm{O}_{3}$ and $\left(80{ }^{\circ} \mathrm{C}\right.$, PGT $\left.=30 \mathrm{~s}\right) \mathrm{Al}_{2} \mathrm{O}_{3}$ as a function of time at $25{ }^{\circ} \mathrm{C}$ and $60 \%$ RH; the inset showed Water Vapor Transmission Rate (WVTR) changes with different film thicknesses.

To further explore the influence of encapsulation thin films on organic devices; OLEDs with a composition of ITO glass/5 nm-thick $\mathrm{MoO}_{3}$ layer; $30 \mathrm{~nm}$-thick 4,4',4"-tris (N-3(3-methylphenyl)-Nphenylamino) triphenyl amine (m-MTDATA) as a hole injection layer; a $20 \mathrm{~nm}$-thick N,N'-biphenyl$\mathrm{N}, \mathrm{N}^{\prime}$-bis(1-naphenyl)-[1,1'-biphenyl]-4,4'-diamine (NPB) as a hole transport layer; a $50 \mathrm{~nm}$-thick tris-(8-hydroxyquinoline) aluminum ( $\left.\mathrm{Alq}_{3}\right)$ as a light-emitting layer and an electron transport layer; and a $1 \mathrm{~nm}$-thick LiF capping with $120 \mathrm{~nm}$-thick Al cathode was prepared and encapsulated via $80 \mathrm{~nm}$-thickness low temperature $\operatorname{ALD}\left(80^{\circ} \mathrm{C}\right.$; PGT $\left.=30 \mathrm{~s}\right)$. The encapsulating-layer was prepared during the same process with the $80 \mathrm{~nm} \mathrm{Al}_{2} \mathrm{O}_{3}$ thin films on Si substrate at $80{ }^{\circ} \mathrm{C}$; ensuring the similarity of properties. The lives of the encapsulated and unencapsulated OLEDs were compared; and the duration decaying from original luminance $\left(1000 \mathrm{~cd} / \mathrm{m}^{2}\right)$ to $50 \%$ was considered as the lifespan of OLED.

Figure 5 depicts the life decay curve of the encapsulated and not encapsulated OLEDs. It shows that the encapsulated OLED has a much longer lifespan, over ten times that of the OLED that was not encapsulated. After ten operating hours the encapsulated OLED showed no apparent change in luminance, though there was an obvious decrease for OLED that was not encapsulated. In addition, after examination of the microscopic pictures of the OLED (the inset of Figure 5), better resistance to corrosion from water vapor and oxygen, and less dark stains occurred at light-emitting areas of the encapsulated OLED. Through comparison of I-V curves of the encapsulated and unencapsulated OLED, the influence of low temperature ALD on device was relatively small. In addition, some organics in the OLED crystallized due to the annealing effect at the preparation temperature, which was suitable for transportation of electrical carrier so that the current and luminance of OLED both increased, as shown in Figure 6. However, we must point that the $\mathrm{Al}_{2} \mathrm{O}_{3}$ thin film can react slightly with water vapor to form $\mathrm{Al}(\mathrm{OH})_{3}[14,24]$, even this reaction was negligible, the encapsulation properties of $\mathrm{Al}_{2} \mathrm{O}_{3}$ thin film may be compromised during long time operation (several years), potentially leading to the formation of defects and pores, and the initiation of dark stains in light-emitting areas. 


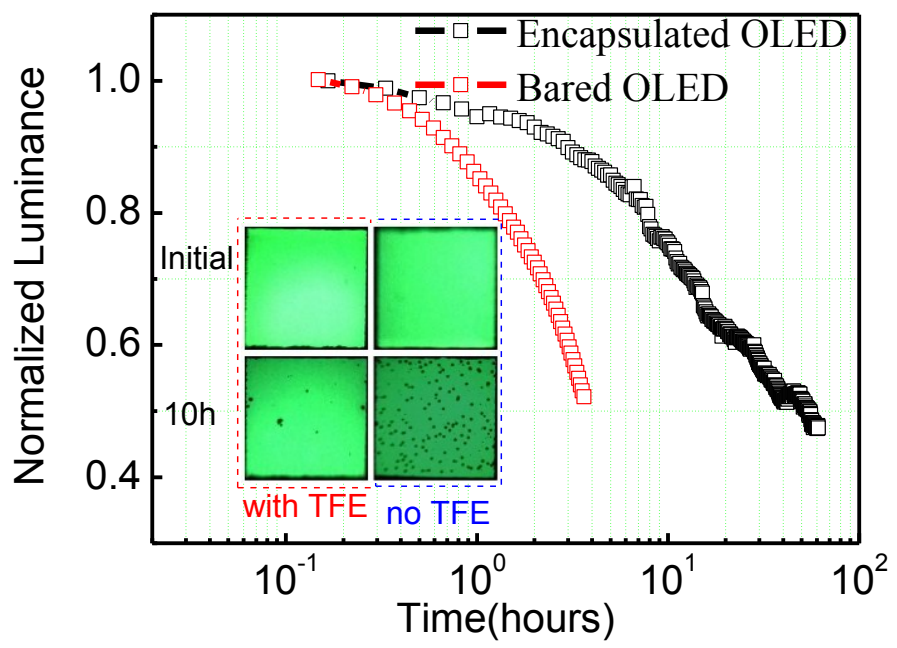

Figure 5. Luminance of OLED encapsulated with and without $\mathrm{Al}_{2} \mathrm{O}_{3}$ thin films as a function of time measured under conditions of $25{ }^{\circ} \mathrm{C}$ and $60 \% \mathrm{RH}$, the inset shows the photos of the test OLEDs after $10 \mathrm{~h}$.

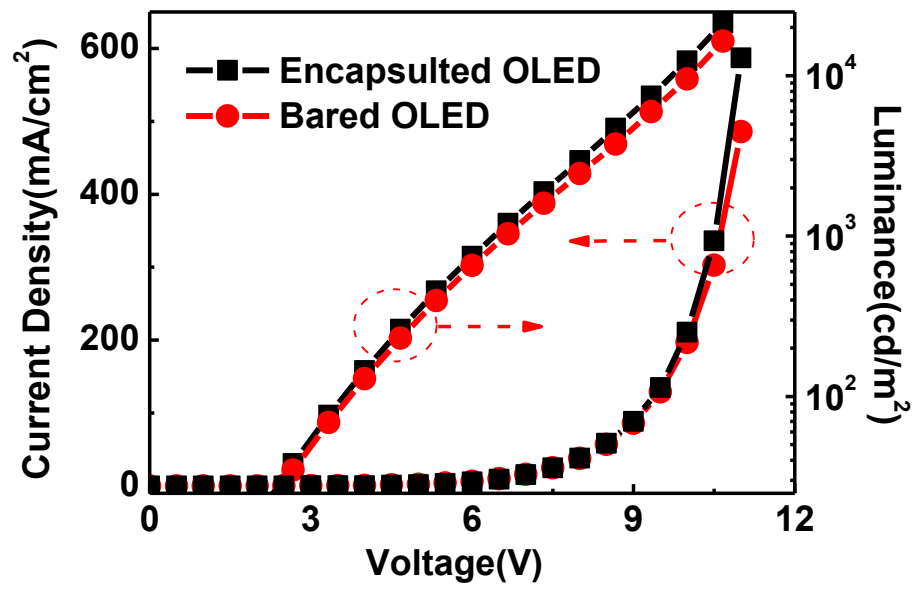

Figure 6. The comparison of I-V characteristics between encapsulated organic light emitting devices (OLED) and bear one.

\section{Conclusions}

In this article, the ALD technique was applied to prepare encapsulated thin films for OLED. A critical hurdle to overcome was the decreasing of WVTR while preserving the organic materials during the preparation process. By adjusting the temperature of the substrates and PGT, the properties of $\mathrm{Al}_{2} \mathrm{O}_{3}$ thin films through low temperature ALD were found to be similar to those at high temperature. The WVTR of single-layered $\mathrm{Al}_{2} \mathrm{O}_{3}$ thin film at $80{ }^{\circ} \mathrm{C}$ was determined by $\mathrm{Ca}$ electrical method to be as small as $1.5 \times 10^{-4} \mathrm{~g} /\left(\mathrm{m}^{2} \cdot\right.$ day $)$, which effectively isolated the material from corrosion by water vapor. It was also found that there was no obvious effect of preparation conditions on the performance of these devices. In the next, we attempt to fabricate TFE using various materials, such as Zirconia, Monox, et al. This study of PGT represents a critical first step in the realization of low temperature ALD for organic electronics. 


\section{Acknowledgments}

This work was supported by Program of International Science and Technology Cooperation (No. 2014DFG12390), National High Technology Research and Development Program of China (Grant No. 2011AA03A110), Ministry of Science and Technology of China (Grant Nos. 2010CB327701, 2013CB834802), National Natural Science Foundation of China (Grant Nos. 61275024, 61274002, 61275033, 61377206 and 41001302), Scientific and Technological Developing Scheme of Jilin Province (Grant Nos. 20140101204JC, 20130206020GX, 20140520071JH), Scientific and Technological Developing Scheme of Changchun (Grant No. 13GH02), Opened Fund of the State Key Laboratory on Integrated Optoelectronics No. IOSKL2012KF01.

\section{Author Contributions}

Hui-Ying $\mathrm{Li}$ and Yi-Nan $\mathrm{Lu}$ whom contributed equally to the manuscript, contributed to the conception of the study and helped perform the analysis with constructive discussions; Yun-Fei Liu performed the data analyses and experiments and wrote the manuscript; Yu Duan contributed to modification of form and grammar; Yong-Qiang Yang performed the experiments.

\section{Conflicts of Interest}

The authors declare no conflict of interest.

\section{References}

1. Li, Q.; Cui, L.-S.; Zhong, C.; Jiang, Z.-Q.; Liao, L.-S. Asymmetric design of bipolar host materials with novel 1,2,4-oxadiazole unit in blue phosphorescent device. Org. Lett. 2014, 16, 1622-1625.

2. Cheng, G.; Chan, K.T.; To, W.-P.; Che, C.-M. Color tunable organic light-emitting devices with external quantum efficiency over $20 \%$ based on strongly luminescent Gold(III) complexes having long- lived emissive excited states. Adv. Mater. 2014, 26, 2540-2546.

3. Mazzeo, M.; della Sala, F.; Mariano, F.; Melcarne, G.; Agostino, S.D.; Duan, Y.; Cingolani, R.; Gigli, G. Shaping white light through electroluminescent fully organic coupled microcavities. Adv. Mater. 2010, 22, 4696-4700.

4. Xiang, C.; Koo, W.; Therefore, F.; Sasabe, H.; Kido, J. A systematic study on efficiency enhancements in phosphorescent green, red and blue microcavity organic light emitting devices. Light Sci. Appl. 2013, 2, e74.

5. Aziz, H.; Popovic, Z.D.; Hu, N.X.; Hor, A.M.; Xu, G. Degradation mechanism of small molecule-based organic light-emitting devices. Science 1999, 283, 1900-1902.

6. Duan, Y.; Sun, F.; Yang, Y.; Chen, P.; Yang, D.; Duan, Y.; Wang, X. Thin-Film barrier performance of zirconium oxide using the low-temperature atomic layer deposition method. ACS Appl. Mater. Interfaces 2014, 6, 3799-3804.

7. Carcia, P.F.; McLean, R.S.; Reilly, M.H.; Groner, M.D.; George, S.M. Ca test of $\mathrm{Al}_{2} \mathrm{O}_{3}$ gas diffusion barriers grown by atomic layer deposition on polymers. Appl. Phys. Lett. 2006, 89, 031915:1-031915:3.

8. Park, J.-S.; Chae, H.; Chung, H.K.; Lee, S.I. Thin film encapsulation for flexible AM-OLED: A review. Semicond. Sci. Technol. 2011, 26, 034001:1-034001:8. 
9. Yamashita, K.; Mori, T.; Mizutani, T. Encapsulation of organic light-emitting diode using thermal chemical-vapor-deposition polymer film. J. Phys. D Appl. Phys. 2001, 34, 740-743.

10. Ham, H.; Park, J.; Kim, Y. Thermal and barrier properties of liquid getter-filled encapsulations for OLEDs. Org. Electron. 2011, 12, 2174-2179.

11. Huang, W.D.; Wang, X.H.; Sheng, M.; Xu, L.Q.; Stubhan, F.; Luo, L.; Feng, T.; Wang, X.; Zhang, F.M.; Zou, S.C. Low temperature PECVD SiNx films applied in OLED packaging. Mater. Sci. Eng. B Solid State Mater. Adv. Technol. 2003, 98, 248-254.

12. Granstrom, J.; Swensen, J.S.; Moon, J.S.; Rowell, G.; Yuen, J.; Heeger, A.J. Encapsulation of organic light-emitting devices using a perfluorinated polymer. Appl. Phys. Lett. 2008, 93, 193304:1-193304:3.

13. Meyer, J.; Schneidenbach, D.; Winkler, T.; Hamwi, S.; Weimann, T.; Hinze, P.; Ammermann, S.; Johannes, H.H.; Riedl, T.; Kowalsky, W. Reliable thin film encapsulation for organic light emitting diodes grown by low-temperature atomic layer deposition. Appl. Phys. Lett. 2009, 94, 233305:1-233305:3.

14. Meyer, J.; Goerrn, P.; Bertram, F.; Hamwi, S.; Winkler, T.; Johannes, H.-H.; Weimann, T.; Hinze, P.; Riedl, T.; Kowalsky, W. $\mathrm{Al}_{2} \mathrm{O}_{3} / \mathrm{ZrO}_{2}$ nanolaminates as ultrahigh gas-diffusion barriers-a strategy for reliable encapsulation of organic electronics. Adv. Mater. 2009, 21, 1845-1849.

15. Kim, H.-K.; Kim, M.S.; Kang, J.-W.; Kim, J.-J.; Yi, M.-S. High-quality thin-film passivation by catalyzer-enhanced chemical vapor deposition for organic light-emitting diodes. Appl. Phys. Lett. 2007, 90, 013502:1-013502:3.

16. George, S.M. Atomic layer deposition: An overview. Chem. Rev. 2010, 110, 111-131.

17. Ghosh, A.P.; Gerenser, L.J.; Jarman, C.M.; Fornalik, J.E. Thin-film encapsulation of organic light-emitting devices. Appl. Phys. Lett. 2005, 86, 223503:1-223503:3.

18. Park, S.H.K.; Oh, J.; Hwang, C.S.; Lee, J.I.; Yang, Y.S.; Chu, H.Y. Ultrathin film encapsulation of an OLED by ALD. Electrochem. Solid State Lett. 2005, 8, H21-H23.

19. Sun, J.-Y.; Ko, Y.-W.; Lim, J.-W. Passivation of organic light-emitting diodes with aluminum oxide thin films grown by plasma-enhanced atomic layer deposition. Appl. Phys. Lett. 2004, 85, 4896-4898.

20. Langereis, E.; Creatore, M.; Heil, S.B.S.; van de Sanden, M.C.M.; Kessels, W.M.M. Plasma-assisted atomic layer deposition of $\mathrm{Al}_{2} \mathrm{O}_{3}$ moisture permeation barriers on polymers. Appl. Phys. Lett. 2006, 89, 081915:1-081915:3.

21. Kim, W.S.; Ko, M.G.; Kim, T.S.; Park, S.K.; Moon, Y.K.; Lee, S.H.; Park, J.G.; Park, J.W. Titanium dioxide thin films deposited by plasma enhanced atomic layer deposition for OLED passivation. J. Nanosci. Nanotechnol. 2008, 8, 4726-4729.

22. Paetzold, R.; Winnacker, A.; Henseler, D.; Cesari, V.; Heuser, K. Permeation rate measurements by electrical analysis of calcium corrosion. Rev. Sci. Instrum. 2003, 74, 5147-5150.

23. Yang, Y.-Q.; Duan, Y.; Chen, P.; Sun, F.-B.; Duan, Y.-H.; Wang, X.; Yang, D. Realization of thin film encapsulation by atomic layer deposition of $\mathrm{Al}_{2} \mathrm{O}_{3}$ at low temperature. J. Phys. Chem. C 2013, 117, 20308-20312.

24. Leskela, M.; Ritala, M. Atomic layer deposition (ALD): From precursors to thin film structures. Thin Solid Films 2002, 409, 138-146.

(C) 2015 by the authors; licensee MDPI, Basel, Switzerland. This article is an open access article distributed under the terms and conditions of the Creative Commons Attribution license (http://creativecommons.org/licenses/by/4.0/). 